\title{
OXYCEPHALY IN BROTHERS
}

BY

M. R. SAWHNEY

LAHORE

AT the end of February, 1933, two boys were brought to the ophthalmic department of the Mayo Hospital, Lahore, Punjab, for a very uncommon defect of the eyes. These two boys were brothers, the younger one aged five years, and the elder aged eleven years.

On examination, I found that both the boys were cases of oxycephaly, their skulls being fairly typical of that condition, as can be seen from their photographs. Their palates were highly arched.

Both of them had fairly well marked bilateral exophthalmos. Both of them had well marked bilateral ptosis, with inability to raise their lids. This interfered with vision to a great extent, so that if they wanted to look at something, they invariably lifted up one lid with the fingers. In fact, the younger of the two went about most of the time with one finger on one or other of the lids to raise it.

In both, the eyes were fixed in the middle line, and there was complete inability to move the eyes in any direction whatsoever,

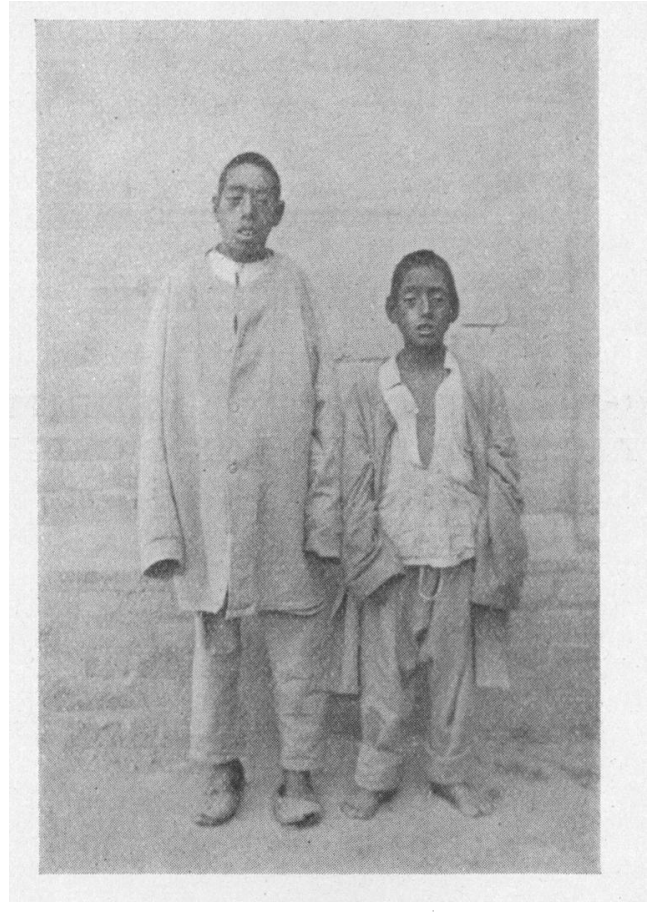


with the result that if they wanted to look anywhere except straight in front they had to move the head.

In each case the vision was practically normal in both eyes. The media and fundi were normal. The fields of vision taken roughly with the hand-a perimetric examination not being possible-were fairly normal.

The boys presented no other abnormality. They came of very poor parents and they had the normal intelligence of their class. The elder one was working with his father in a brick kiln.

- As regards the family history, their parents were quite normal. They had two brothers, one younger whom I saw, and one older whom I did not see. The younger one, aged two years, was quite normal, and I am told that the elder one as well as two sisters was quite normal.

I have seen cases of oxycephaly before, but this is the first instance in which I have seen two brothers suffering from the same defect. Exophthalmos is usual, but this is the first instance in which I have seen ptosis with fixation of the eyeballs in the centre, and complete lack of movements of the eyeballs in any direction.

I am unable to lay my hands on all the literature on oxycephaly and hence do not know if such a defect has been recorded before. In any case I think the cases are rare enough and worth recording.

The question arises as to whether the ptosis and fixation of the eyeballs was due to mal-development of the muscles or the nerves. It seems to me that the defect was in the muscles. Lack of movement was certainly not due to exophthalmos. The condition was congenital, and the defect was noticed at birth. Skiagrams were of no help.

THERAPEUTIC NOTE

\section{CHRONIC RETROBULBAR NEURITIS AND AMBLYOPIAS OF TOXIC ORIGIN}

\section{A New Methód of Treatment}

BY

N. N. RaY, M.B., D.O.M.S.(Lond.)

LATE HON. OPHTHALMIC SURGEON, CAMPBELL HOSPITAL, CALCUTTA

IN course of hospital and private practice oculists come across a number of cases with impaired vision, the correction of whose refractive error, usually small and very disproportionate in comparison to the defect of sight-does not improve the vision at 